\title{
Effects of zinc supplementation on nutritional status and cognition in children
}

\author{
Retno Asih S, Endang Warsiki, Boerhan Hidajat
}

\begin{abstract}
Background Zinc deficiency is common in children in developing countries and data suggests the effects are detrimental towards children's growth and neuropsychologic performance. Results of multiple studies which assess these effects have been inconsistent.

Objective To evaluate the effects of zinc supplementation on nutritional status and cognition in children with zinc deficiency.

Methods Forty-six stunted children aged 50-80 months with low hair zinc levels were randomly assigned to receive either $7.5 \mathrm{mg}$ elemental $\mathrm{Zn}$ or placebo twice a week for 3 months. Anthropometry and cognition were assessed at the beginning and the end of the supplementation period. Differences among both groups for anthropometry and cognition before and after supplementation were analyzed with paired t-test. A comparison of different anthropometry and cognition among the two groups were analyzed using the independent t-test.

Results There were no significant differences among baseline characteristics except on sex distribution. There was a significant difference in weight for age between the zinc group and placebo [0.28 (SB 0.18) vs 0.09 (SB 0.14); $P=0.0001]$. Height increments were also greater in the zinc group [0.34 (SB 0.15) vs 0.02 (SB $0.12) ; P=0.0001)$. There was no significant difference between weight for height. Intelligence quotient (IQ) measured by the Stanford-Binnet test was slightly higher in the zinc group [2.26 (SB 3.11 ) vs 2.00 (SB 2.81], but the difference was not significant according to sex.

Conclusion Zinc supplementation produced highly positive responses in weight for age and height for age increments in children with zinc deficiency compared with placebo. There was no effect of zinc supplementation on weight for height index and none on cognition measured by intelligence quotient (IQ) [Pediatr Indones 2006;46:64-70].
\end{abstract}

Keywords: zinc deficiency, zinc supplementation, nutritional status, cognition
A

pproximately one-half of children $<5$ years of age in developing countries are retarded in statural growth. Infections and inadequate food intake are common causes of stunting; however, the possible role of individual micronutrient deficiencies, particularly zinc, in the etiology of growth retardation has gained attention recently. ${ }^{1-3}$ Zinc is an essential trace element which affects growth by promoting DNA and RNA synthesis and cell division. ${ }^{4}$ In fact, more than 100 enzymes require zinc as a cofactor. ${ }^{5,6}$

Nutritional zinc deficiency was first documented in the Middle East in 1963, and in the following two decades. Reports from Iran, Egypt, Turkey, Portugal, Morrocco, Yugoslavia, and other developing countries, as well as the United States and Canada, have shown that nutritional deficiency is fairly prevalent throughout the world. These reports do not represent the actual incidence of zinc deficiency worldwide, yet reflect awareness in diagnosing overt cases only. Hence

Presented at $13^{\text {th }}$ National Child Health Congress, Bandung, Indonesia, July 4-7, 2005.

From the Department of Child Health, Airlangga University, Surabaya, Indonesia (RAS, BH); Department of Psychiatry, Airlangga University, Surabaya, Indonesia (EW).

Reprint requests to: Retno Asih S, MD, Department of Child Health, Medical School, Airlangga University, Soetomo Hospital, Jl. Prof. dr. Moestopo 4-6, Surabaya, Indonesia. Tel. 62-31-5501748. Fax. 62-315501680. 
zinc deficiency could be prevalent in other countries but remains undiagnosed. ${ }^{6}$ Zinc status is difficult to assess since plasma zinc concentrations do not sufficiently reflect individual zinc status due to strong homeostasis. ${ }^{7}$ There is no acceptable single index to measure zinc deficiency; rather, it is necessary to demonstrate a favorable response to zinc supplementation. Little is known about the zinc status of Indonesian children. In an earlier study in Indonesia, $25 \%$ of lactating mothers and $17 \%$ of their infants had low plasma zinc concentration. ${ }^{7}$ The study was conducted on low income families in Wonokromo, Surabaya were $87.5 \%$ stunted children $1-3$ years of age showed low hair zinc level. ${ }^{8}$ The results of zinc supplementation trials in children, however, are inconsistent. ${ }^{9-12}$

There is some concern that zinc deficiency may also be detrimental towards child development and behavior although many of the studies give unconsistent result. ${ }^{14-18}$ We designed a randomized double blind intervention study to evaluate the effect of zinc supplementation on nutritional status and cognitive function in children with zinc deficiency.

\section{Methods}

This was a randomized, double-blind, placebo-controlled trial on stunted children (less than -2 SD zscore height for age) 50-80 months of age and normal weight for height at recruitment. Supplementation was given twice a week for 3 months. Children were recruited from 12 kindergartens in Ngagelrejo, Wonokromo, Surabaya. The prevalence of weight for age less than -2 SD of children $<5$ years in the area was $14.8 \%$.

One hundred thirty six stunted children aged 50-80 months with normal weight for height $z$-score were recruited on February-May 2004. Among them, 52 children (38\%) had low zinc hair level (WHO standard).

Two groups of children were supplemented with syrup containing elemental zinc $7.5 \mathrm{mg} /$ day (zinc sulfas $0.37 \%$ in syrup) or placebo. Supplements were made by a local pharmaceutical company (Sri Mentari's dispensary, Sidoarjo, East Java) recommended by Nutrition Academy, Surabaya. Supplements were indistinguishable and both contained sugar, citric acid, and artificial flavors. The study was carried out in
Ngagelrejo, an urban area of Surabaya, East Java, Indonesia between June-September 2004.

Eligible children were identified by health volunteers and researchers, and mothers were invited to participate in the study. Parents were informed of procedures and purpose of the study. Written informed consents were collected from parents, afterwards children were assessed anthropometrically and a short history was taken concerning dietary and health of the child; answers to questionnaires were recorded. Questionnaires included data on family income, maternal education and occupation, number of siblings, and parenting style.

Exclusions included chronic or severe illness, such as neoplasm, congenital anomalies, or hearing and visual disorder. Children were assigned to one of the two supplementation groups by using simple randomization by numeric random table.

Supplementation was double-blinded, the supplements were coded with a specific mark and the code-allocation was safely kept by the researcher. Zinc supplementation or placebo began after the first anthropometry measurement, and cognitive function assessed by the Stanford-Binnet test were obtained.

At recruitment, all subjects received a personal bottle with a dosing syringe. The bottles were monitored by health volunteers. Mothers were instructed to feed the syrup every night before her child went to sleep and were also instructed to keep the bottle after it was empty. Every month, health volunteers provided a monthly supply of the syrup to subjects' homes and quantified what had been consumed the month before. Compliance with zinc supplement/placebo intake was evaluated, subjects whose monthly zinc intake was $<50 \%$ of the prescribed volume were excluded.

At monthly follow-ups, subjects were assessed anthropometrically and a short history concerning health and possible adverse effects was taken. Anthropometry included measurement of weight and height by trained health volunteers using standard methods. Anthropometry was recorded monthly; weight was measured with 10 grams error in a Seca scale. Height was expressed in centimeters to 1 decimal measured with microtoise. Weight for age, height for age, and weight for height $z$-score were calculated according to the National Center for Health Statistics reference data for age and sex. 
The cognition was assessed by Stanford-Binnet test at the beginning and the end of supplementation. The Stanford-Binnet is the most commonly used cognitive test with intelligence quotient (IQ) as an outcome. The test was evaluated by a trained psychologist from the Psychiatry Department, Soetomo Hospital, Surabaya. Other more common methods such as Infant Bayley Scales was inapplicable due to limitations of resources and personal capabilities.

Hair specimens were collected from the lower occipital scalp. The instructions specified that the specimens should be taken from the edge near to the scalp with $<1 \mathrm{~cm}$ in length. Specimens were transported to the Health District Laboratory (Laboratorium Kesehatan Daerah) for zinc analysis using AAS (Atomic Absorbic Spectrophotometry). According to WHO standards, levels less than $150 \mathrm{mg} / \mathrm{kg}$ was considered as low hair zinc level.

The protocol was approved by the Research Committee, (Badan Kesatuan Bangsa dan Perlindungan Masyarakat) Surabaya, East Java.

Data were checked for normal distribution using the Kolmogorov-Smirnov test of normality. Differences among both groups for anthropometry and cognition before and after supplementation were analyzed with paired t-test. The comparison of the differences in anthropometry and cognition among the two groups were analyzed using the independent sample t-test. Analyses were performed using SPSS (Version 11.0 for Windows)

\section{Results}

A total of 52 children were recruited and 46 children completed the supplementation trial. Six ( 3 from the zinc group and 3 from placebo group) subjects dropped out during the study for various reasons, such as moved out and poor compliance.

There were no significant differences between the groups in age, family income, maternal education and occupation, number of sibling, and parenting style. Sex distribution was significantly different between zinc group and placebo group $(\mathrm{P}=0.039)$, thus the next analysis was based on sex. Since anthropometry measurements expressed in $z$-score were calculated according to the National Center for Health Statistics reference data for age and sex, only cognition differentiated based on the sex (Table 1).
There were no significant differences towards initial nutritional status between zinc group and placebo group.

Monthly changes of weight for age and height for age in the zinc group were significant until the end of supplementation (Table 2).

If nutritional status in both groups were compared, there were significant differences on weight for age and height for age. The difference of weight for height until the end of supplementation was not significant. At the end, weight for age in the zinc group was higher than that of the placebo group [0.28 (SD 0.18) vs 0.09 (SD 0.14); $\mathrm{P}=0.0001$ ] (Figure 1). Height for age in the zinc group (Figure 2) was higher than the placebo group [0.34 (SD 0.15) vs 0.02 (SD 0.12); $\mathrm{P}=0.0001$ ].

There were no significant differences on initial cognition between the zinc group and the placebo group, changes of cognition in the zinc group and placebo group before and after supplementation were significant $(\mathrm{P}=0.002, \mathrm{P}=0.003$, respectively)

IQ (mean $\pm \mathrm{SD}$ ) in the zinc group was slightly higher than that of the placebo group, $2.26 \pm 3.11 \mathrm{vs}$ $2.00 \pm 2.81$, yet the difference was not significant according to sex.

TABle 1. Baseline characteristics of the subjects

\begin{tabular}{lcc}
\hline Variables & \multicolumn{2}{c}{ Group } \\
\cline { 2 - 3 } & Zinc & Placebo \\
\hline Age (months) & 63.7 (SD 9.40) & 67.6 (SD 9.06) \\
Sex & & \\
$\quad$ Male & 16 & 8 \\
$\quad$ Female & 7 & 15 \\
Family income (rupiah) & 17 & 17 \\
$\quad$ 1 000.000 & 6 & 6 \\
$\quad>1$ 000.000 & 3 & 5 \\
Maternal education & 8 & 4 \\
$\quad$ Elementary school & 11 & 9 \\
$\quad$ Junior high school & 1 & 5 \\
$\quad$ Senior high school & & \\
$\quad$ University & 5 & 8 \\
Maternal occupation & 18 & 15 \\
$\quad$ Yes & & \\
$\quad$ No & 14 & 5 \\
Number of sibling & 5 & 6 \\
$\quad<3$ children & 4 & - \\
$\quad$ 3-5 children & & 9 \\
$\quad>5$ children & - & \\
Parenting style & 8 & \\
$\quad$ Authoritarian & 15 & \\
$\quad$ Authoritative & & \\
Permissive & & \\
\hline & &
\end{tabular}


Retno Asih S et al: Effects of zinc supplementation on nutritional status and cognition

Table 2. Changes in nutritional status of zinc and placebo groups AFTER A 3-MONTH FOLLOW-UP PERIOD

\begin{tabular}{llll}
\hline $\begin{array}{l}\text { Nutritional } \\
\text { status } \\
\boldsymbol{z} \text {-score }\end{array}$ & $\begin{array}{c}\text { Initial } \\
\text { mean (SD) }\end{array}$ & $\begin{array}{c}\text { End of study } \\
\text { mean (SD) }\end{array}$ & P Value \\
\hline $\begin{array}{l}\text { Weight for age } \\
\text { Zinc }\end{array}$ & $-2.19(0.58)$ & $-1.91(0.60)$ & $\mathrm{P}=0.0001$ \\
$\quad$ Placebo & $-2.37(0.50)$ & $-2.29(0.54)$ & \\
& & & \\
Height for age & $-2.38(0.45)$ & $-2.04(0.48)$ & $\mathrm{P}=0.0001$ \\
$\quad$ Zinc & $-2.68(0.67)$ & $-2.67(0.68)$ & \\
$\quad$ Placebo & & & \\
$\begin{array}{l}\text { Weight for height } \\
\text { Zinc }\end{array}$ & $-1.04(0.66)$ & $-0.66(0.90)$ & \\
$\quad$ Placebo & $-1.11(0.82)$ & $-1.02(1.04)$ & \\
\hline
\end{tabular}
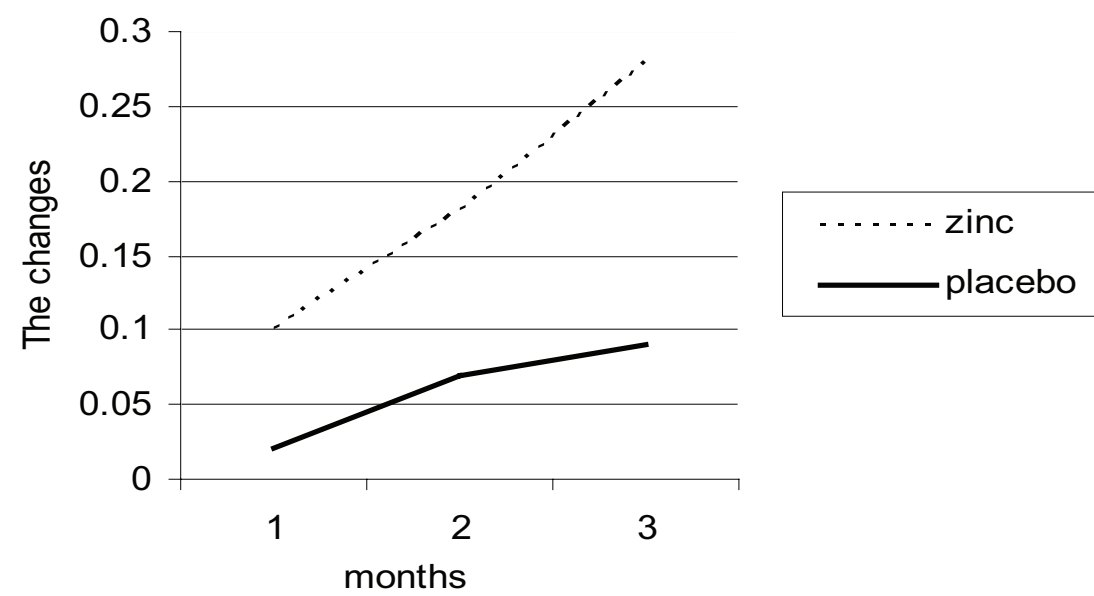

Figure 1. WeIGHT FOR Age (Z-SCORE) DURING SUPPLEMENTATION PERIOD.

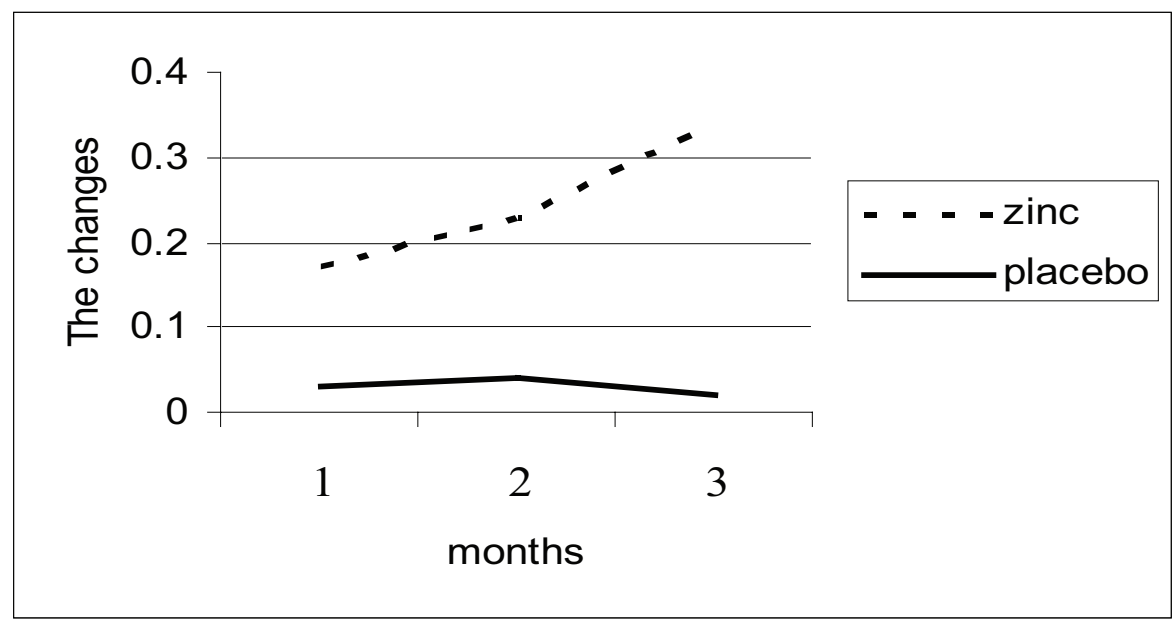

Figure 2. Height for age (Z-score) duRing SUPPLEMENTATION PERIod. 
If the correlation between nutritional status and cognition during supplementation period was analyzed there was no significant correlation between nutritional status (weight for age, height for age, and weight for height) and cognition.

\section{Discussion}

Our study shows that zinc supplementation in stunted children with zinc deficiency promotes growth, especially towards weight for age and height for age. Since there is no single useful biochemical measurement which detects marginal zinc deficiency in humans, the effect of zinc supplementation on linier growth has been proposed to be a reliable functional index of zinc status in children. Our observation of improvements towards linear growth during zinc supplementation at physiological doses supports the existence of zinc deficiency in these children. Several lines of evidence suggest that their zinc status was marginal or low. First, virtually Indonesian children, especially from low social-economic status are suspected of having inadequate zinc intake since most consume limited animal products which are main sources of zinc. Second, high consumption of legumes and rice may preclude adequate zinc absorption since their high phytate and fiber contents. Third, gastrointestinal diseases (diarrhea, parasites) may increase intestinal losses of zinc. ${ }^{7}$

In our study, zinc supplementation accelerated weight and height gain simultaneously. Most zinc supplementation trials in the United States and Canada on short but well-nourished children did not report a stimulatory effect on weight gain. ${ }^{10}$ Our findings, however, agree with those of trials performed in malnourished population in developing countries where zinc supplementation increased weight and height. 1,8,19

Although our observations show that zinc supplementation stimulated growth, the mechanisms for this effect is unknown. The effect of zinc may result from increased appetite ${ }^{8,19}$ and improved ingestion of energy and/or protein. Unfortunately, changes in energy intake are difficult to asses in children by recall method. Nevertheless, increased appetite is not a consistent clinical feature of zinc supplementation. ${ }^{13,20}$ Zinc may promote growth through changes in protein synthesis and cell replication, contributing to accumulation of lean tissue. ${ }^{21}$
Morbidity by infectious diseases was not investigated in this study. Changes in the occurrence of infectious diseases have not been investigated in most zinc supplementation studies. Zinc deficiency, however, is one of the most frequent and correctable causes of acquired immunodeficiency diseases. In a previous study, immune functions of malnourished children, as evaluated by salivary or serum immunoglobulin concentration and hypersensitivity skin test responses, was generally improved by zinc supplementation. ${ }^{20}$ This reduction of infection incidence raises the possibility that zinc's effect on statural growth may be mediated, in part, by a reduced incidence of infections.

The significance of body weight in the placebo group after supplementation period was achieved. This may be due to the increase of daily consumption after external motivation of the parents by information provided by the researcher (the placebo effect or masking effect). However, in zinc deficiency, instead of lean tissue accumulation adipose tissue accretion will take place.

There was no impact of zinc supplementation on changes in weight for height $z$-score, this may indicate that supplemental zinc is more likely to influence linear growth than accrual of fat mass, yet the number of available studies remains limited. ${ }^{22}$

Few studies have analyzed the effect of zinc deficiency on cognition in humans. Sazawal et al ${ }^{23}$ reported a positive effect of zinc supplementation on activity scores among infants 12-24 months of age in the peri-urban community of North India. In this randomized trial, a 6 day/week oral dose of $5 \mathrm{ml}$ zinc gluconate (10 mg elemental zinc) was administered for 6 months with double doses given during diarrheal episodes. ${ }^{23}$ There was a positive effect of zinc-combined micronutrient supplementation on neuropsychological performance in Chinese children 6-9 years of age which was consumed for 10 weeks compared to micronutrients alone. ${ }^{18}$

Iron levels may influence the development of cognition. However, in our study, we assume that this factor could be disregarded since our sample came from a certain area with similarities in social-economic status.

There was no effect of zinc supplementation on cognition measured by intelligence quotient (IQ) in our study. Various factors can be analyzed:

1. The Stanford-Binnet test contained more verbal content, therefore it may be difficult to conduct by children with language disorders 
Retno Asih S et al: Effects of zinc supplementation on nutritional status and cognition

2. Other clinical aspects of cognition, such as attention and recognition, are difficult to be examined by the Stanford-Binnet test. Unfortunately, another more common method such as the Infant Bayley Scales was inapplicable due to limitations of resources and personal capabilities.

3. At the beginning of the supplementation period, both samples have the mean normal IQ, therefore it is difficult to achieve a higher level or higher IQ.

4. The time of supplementation may be short. The 3 -month period of zinc supplementation which we used in our study was based on a study in urban and rural Chinese children which was 10 weeks. ${ }^{18}$

Our study showed that there was no correlation between nutritional status and cognition, possibly since the length of study was not enough to explore and perhaps the Stanford-Binnet test can not examine other clinical aspects of cognition, such as attention and recognition.

In conclusion, we found a positive effect of a 3month zinc supplementation on linier growth of stunted children ages 50-80 months. An overall group effect was documented on weight for height, suggesting effects of zinc supplementation on accretion of fat free mass. The results indicate that interventions aimed at improving the zinc status of children may be important effects on growth, particularly if the interventions are focused on the most stunted children. Further research is required to explore whether supplementation with longer periods of time may achieve larger and more generalized effects. In addition, the possibility that nutrients other than or in addition to zinc may be limiting the growth of children should be evaluated. A possible application of our findings to public health programs is the use of stunting for the selection of beneficiaries of interventions involving supplementation or food fortification with zinc. In this study, there was no effect of zinc supplementation on cognition measured by intelligence quotient.

\section{Acknowledgments}

We are grateful to the children and their parents who participated in the study and also to Benny Soegianto, MD; Mrs. Mundiastuti; and Mr. Saiful for their assistance.

\section{References}

1. Ninh NX, Thissen JP, Collette L, Guy G, Khoy HH, Marie J. Zinc supplementation increases growth and circulating insulin-like growth factor (IGF-I) in growth retarded Vietnamese children. Am J Clin Nutr 1996;63:514-9.

2. Rivera JA, Ruel MT, Santizo MC, Lõnnredal B, Brown $\mathrm{KH}$. Zinc supplementation improves the growth of stunted rural Guatemalan infants. J Nutr 1998; 128:556-62.

3. Rahman MM, Tofail F, Wahed MA, Fuchs GJ, Baqui $\mathrm{AH}$, Alvarez JO. Short-term supplementation with zinc and vitamin $\mathrm{A}$ has no significant effect on the growth of undernourished Bangladeshi children. Am J Clin Nutr 2002;75:87-91.

4. Siklar Z, Tuna C, Dallar Y, Tanyer G. Zinc deficiency: A contributing factor of short stature in growth hormone deficient children. J Trop Pediatr 2003;49:187-8.

5. Hambidge M. Human zinc deficiency. J Nutr 2000; 130:1344-9.

6. Bahijri SM. Serum zinc in infants and preschool children in the Jeddah area: Effect of diet and diarrhea in relation to growth. Available from: URL: http://www.kfshrc.edu.sa/annal/215_216/01. 017 sr.htm.

7. Dijkhuizen MA, Wierenga FT, West CE, Martuti S, Muhilal. Effects of iron and zinc supplementation in Indonesian infants on micronutrient status and growth. J Nutr 2001;131:2860-5.

8. Mundiastuti L. Pengaruh pemberian suplemen seng (Zn) terhadap status gizi anak usia 1-3 tahun di kelurahan Bendul Merisi, Kecamatan Wonocolo dan di Kelurahan Jagir, Kecamatan Wonokromo, Kota Surabaya [thesis]. Surabaya: Program Pasca Sarjana Universitas Airlangga; 2002.

9. Nakamura T, Nishiyama S, Futagoishi-Suginohara Y, Matsuda I, Higashi A. Mild to moderate zinc deficiency in short children: Effect of zinc supplementation on linear growth velocity. J Pediatrics 1993;123:65-9.

10. Walfarens PA, Chakar A, Mokni R, Denise J, Lemonnier D. Zinc supplements in breastfed infants. Lancet 1992;340:683-5.

11. Meeks GJ, Witter MM, Ramdath DD. Zinc supplementation: Effect on the growth and morbidity of undernourished Jamaican children. Eur J Clin Nutr 1998;52:34-9.

12. Rosado JL. Lopez P, Munoz E, Martinez H, Allen LH. 
Zinc supplementation reduced morbidity, but neither zinc nor zinc supplementation affected growth or body composition of Mexican preschoolers. Am J Clin Nutr 1997;65:13-9.

13. Schlesinger L, Arevalo M, Arredondo S, Diaz M, Lõnnredal B, Sketel A. Effect of zinc-fortified formula on immunocompetence and growth of malnourished infants. Am J Clin Nutr 1992;56:491-8.

14. Hamadani JD, Fuchs GJ, Osendarp SJ, Khatun F, Huda SN, Granthom SM. Randomized controlled trial of the effect of zinc supplementation on the mental development of Bangladeshi infants. Am J Clin Nutr 2001;74:381-6.

15. Golub MS, Keen CL, Gershwin ME, Heiydrick AG. Developmental zinc deficiency and behaviour. J Nutr 1995;125:2263-71.

16. Cavan KR, Gibson RS, Grazioso CF. Growth and composition of periurban Guatemalan children in relation to zinc status: A cross sectional study. Am J Clin Nutr 1993;57:334-43.

17. Gibson RS, Vanderkooy PDS, Donald AC, Goodman A, Ryan BH, Berry M. A growth limiting, mild zinc deficiency syndrome in some Southern Ontario boys with low height percentile. Am J Clin Nutr 1989; 49:1266-73.
18. Sandstead H, Penland JG, Alcock NW, Dayal HH, Chen $\mathrm{XC}, \mathrm{Li} \mathrm{JS}$, et al. Effects of repletion with zinc and other micronutrients on neuropsychologic performance and growth of Chinese children. Am J Nutr 1998; 68(suppl):470s-5s.

19. Cun CX, An YT, Sheng HJ, Yan MQ, Min HZ, Xiang LL. Low levels of zinc in hair and blood, pica, anorexia and poor growth in Chinese preschool children. Am J Clin Nutr 1985;42:694-700.

20. Castilo D, Heresi G, Fisberg M, Uauy R. Controlled trial of zinc supplementation during recovery from malnutrition: Effect on growth and immune function. Am J Clin Nutr 1987;45:602-8.

21. Prasad AS. Discovery of human zinc deficiency and studies in an experimental human model. Am J Clin Nutr 1991;53:403-12.

22. Brown KH, Allen LH, Peerson JM, Rivera J. Effect of supplemental zinc on growth and serum zinc concentrations of pre-pubertal children: A meta-analysis of randomized controlled trials. Am J Clin Nutr 2002;75:1062-71.

23. Sazawal S, Bentley M, Black R, George S, Dhingra P, Bhan MK. Effect of zinc supplementation on observed activity in low social economic Indian preschool children. Pediatrics 1996;98:1132-7. 